\title{
The Role of p16, p21, p27, p53 and Ki-67 Expression in the Differential Diagnosis of Cutaneous Squamous Cell Carcinomas and Keratoacanthomas: An Immunohistochemical Study
}

\author{
Recep Bedir ${ }^{1}$, Hasan Güçer ${ }^{1}$, İbrahim Şehitoğlu ${ }^{1}$, Cüneyt Yurdakul ${ }^{1}$, Pelin Bağc1 ${ }^{2}$, Pelin Üstüner ${ }^{3}$ \\ ${ }^{1}$ Department of Pathology, Recep Tayyip Erdoğan University School of Medicine, Rize, Turkey \\ ${ }^{2}$ Department of Pathology, Marmara University School of Medicine, İstanbul, Turkey \\ ${ }^{3}$ Clinic of Dermatology, Rize State Hospital, Rize, Turkey
}

Background: Distinguishing squamous cell carcinoma (SCC) from keratoacanthoma (KA) by histopathological features may not be sufficient for a differential diagnosis, as KAs may, in some cases, imitate well-differentiated SCCs.

Aims: In this study, we investigated whether the expression of the p16, p21, p27, p53 genes and a Ki-67 proliferation index are useful in distinguishing between these two tumors.

Study Design: Cross-sectional study.

Methods: Immunohistochemistry was used to investigate the expression of the p16, p21, p27, p53 genes and the Ki-67 proliferation index was investigated in well-differentiated SCC with KA-like features $(n=40)$ and $\mathrm{KA}(\mathrm{n}=30)$.

Results: The results of all of the examined markers, except for p27 (p16, p21, p53, and Ki-67) were found to be significantly different between the SCC and KA samples $(\mathrm{p}<0.05)$.

Conclusion: In well-differentiated SCC with KA-like features and KA cases where the differential diagnosis is difficult from a histopathological perspective, the use of $\mathrm{p} 16$, p21, p53 expression and a Ki-67 proliferation index can be useful for the differential diagnosis of SCCs and KAs.

Keywords: Differential diagnosis, immunohistochemistry, keratoacanthoma, skin, squamous cell carcinoma
Squamous cell carcinoma (SCC) is the second most common malignancy observed in humans after basal cell carcinoma (BCC). The possibility of metastasis and death is higher in SCC than in BCC. As a widely observed benign skin neoplasm, keratoacanthoma (KA) exhibits similarities with SCC in terms of both clinical and histopathological features $(1,2)$. KAs are typically seen on sun-exposed regions and frequently in middle-aged and elderly people as well as those that are sensitive to light. The characteristic findings of KAs are rapid clinical growth (6 weeks) and spontaneous disappearance after 1 year. Although KAs are known to be benign, some authors accept them as a variant of SCC. Some KA cases that were initially diagnosed as benign progressed to be metastatic, exhibiting aggres- sive behavior (3-5). The immunohistochemical markers that have been used for years to distinguish between SCC and KA in studies are: p53, proliferating cell nuclear antigen telomerase and COX-2 transforming growth factor- $\alpha$, angiotensin-type I receptor, vascular cell adhesion molecule, intercellular adhesion molecule, Ki-67, p16 tumor suppressor antigen, matrix metalloproteinases, syndecan-1 and Bcl-2 (6-15). However, none of these studies have been able to provide reliable and specific criteria with which to distinguish between these two tumors.

P16 is a tumor-suppressor protein encoded by the INK $4 \alpha$ gene located on chromosome 9p21. The expression of p16 in the keratinocytes in the epidermis is induced by low- and high-doses of ultraviolet $\mathrm{B}$ radiation (12). 
The $\mathrm{p} 21$ protein exists in a complex with proliferating cell nuclear antigen (PCNA), cyclin-dependent protein kinase (CDK) and cyclin. It has been suggested that the $\mathrm{p} 21$ protein controls p53 induction in cell cycle arrest induced by DNA damage (16). The p21 protein blocks the initiation of DNA replication by inhibiting the CDK complex. It can also block the progression of PCNA. The p21 protein has also been reported to play a role in decreasing cellular proliferation and blocking p53 activation $(16,17)$.

The $\mathrm{p} 27$ protein is structurally homologous to the $\mathrm{p} 21$ protein; p27 expression leads to the arrest of the cell cycle, and is increased by growth inhibition signals, while it is decreased by growth stimulating signals, leading to cell cycle progression (18).

The p53 tumor suppressor protein is an important transcription factor in the arrangement of cellular cycle mechanisms. The p53 gene plays a critical role in maintaining a controlled cell division and is the gene subjected to mutations in malignancies. The activation of this gene is considered to be the key event triggering human carcinogenesis. Abnormal p53 expression has been observed in lichen planus, psoriasis, chronic dermatitis, lupus erythematosus, and the inflammatory diseases of squamous epithelium. This indicates that the p53 protein plays an important role in controlling cellular proliferation. It has also been frequently detected in cutaneous SCCs $(19,20)$.

$\mathrm{Ki}-67$ is found in the G1, S, G2 and M-phases of the cell cycle. However, it is not detectable in G0 cells. There is a strong correlation between various cellular proliferation indices and Ki-67 immunoreactivity (16).

In this study, we investigated the expression of the p16, p21, p27 and p53 genes and the Ki-67 proliferation index in the differential diagnosis of well-differentiated SCC with KA-like features and KA cases.

\section{MATERIALS AND METHODS}

The study protocol was reviewed and approved by the Local Ethical Clinical Committee in Recep Tayyip Erdoğan University School of Medicine in Turkey (Approval date: 23 November 2012; meeting number: 2012/155). The study involved the use of formalin-fixed paraffin-embedded tissue sections of histopathologically diagnosed cases of well-differentiated SCC with KA-like features $(n=40)$ and KA $(n=30)$ from the archives of the Department of Pathology. The slides that had been stained with hematoxylin and eosin were re-evaluated to confirm the diagnoses. For the microscopic differential diagnosis of KA and SCC, we considered the following findings. Keratoacanthomas were composed of singularly well-differentiated squamous epithelium that shows only a mild degree of pleomorphism and are likely to form masses of keratin that constitute the central core of KA. Typical SCCs had nests of squamous epithelial cells arising from the epidermis and extending into the dermis accompanied with keratin pearls. The malignant cells were often large with abundant eosinophilic cytoplasm and a large, often vesicular nucleus. Information regarding the gender and age of the patients was obtained from the Medical Records office of the Department. Five micronthick serial sections were obtained from the paraffin-embedded blocks of the selected preparations and fixed using formalin on a positively charged slide to perform immunohistochemistry (IHC) on p16, p21, p27, p53 and Ki-67. In this study, primary antibodies to p16 (clone Cocktail, A00098, Biocare Medical, 1: 100 dilution; Logan, Utah USA), p21 (clone V9, A00045, Cell Marque, 1: 100 dilution; Logan, Utah USA), p27 (clone COL-1, PM058AA Cell Marque, 1: 50 dilution; Logan, Utah USA ), p53 (clone DO-7, ScyTec, 1: 50 dilution, Logan; Utah USA) and Ki-67 (clone 4C4.9 A00087, ScyTec, 1:100 dilution; Logan, Utah USA) were used. The biotin-free, HRP multimer-based, hydrogen peroxide substrate and 3,3'-diaminobenzidine tetrahydrochloride (DAB) chromogen containing ultraView $^{\mathrm{TM}}$ Universal DAB Detection Kit (Catalog number 760-091, Ventana Medical Systems; Tucson, AZ, USA) and a fully automated immunohistochemistry staining device (Ventana BenchMark XT, Ventana Medical Systems; Tucson, AZ, USA) were used as the IHC staining system. The whole IHC staining process, including the deparaffinization and antigen revealing procedures, was performed using the Bench Mark $\mathrm{XT}$ and a fully automated IHC staining device. Only the primary antibodies p16, p21, p27, p53 and Ki-67 were manually placed as drops and incubated at $37^{\circ} \mathrm{C}$ for 30 minutes. The sections were counterstained with Mayer's Hematoxylin. Simultaneously, the known positive controls were also stained. The sections were examined under light microscopy.

\section{Assessment of immunostaining}

For the assessment of immunostaining, a semi-quantitative approach was used based on the proportion of positively stained cells as follows: Grade 1 (weak staining), $<10 \%$ of positive cells; Grade 2 (moderate staining), $10-50 \%$ of positive cells; and Grade 3 (strong staining), $>50 \%$ of positive cells. Staining intensity was evaluated in the non-invasive area of SCCs and KAs. The IHC-staining pattern was classified as: level 1 (basal and supra-basal layer); level 2 (level $1+$ midzone); and level 3 (full thickness expression) (21). The staining intensity and patterns were scored by two pathologists. Immunostaining grading results of p16, p21, p27, p53 and $\mathrm{Ki}-67$ were quantified by expressing the number of positive keratinocytes as a percentage of 1000 cells counted in each section. At least three microscopic fields were evaluated 
for scoring. The counting fields were randomly selected. Only nuclear staining for p21, p27, p53, and Ki-67 also nuclear and cytoplasmic staining pattern for $\mathrm{p} 16$ was accepted as positive.

\section{Statistical analysis}

Statistical assessments were performed using the SPSS software (SPSS version 16, SPSS Inc.; Chicago, IL, USA). Continuous variables were expressed as mean \pm SD together with the range (minimum-maximum). For the comparison of the two groups, the Mann-Whitney U test was used. The numerical variables showing non-parametric distribution were assessed using Spearman's correlation analysis. The comparison of categorical variables was performed using the Chi-square test. $\mathrm{P}<0.05$ was accepted as statistically significant.

\section{RESULTS}

The mean ages of SCC and KA cases were 74 (range 39-92) and 71 years (35-8), respectively. Overall, $53 \%$ of the SCC cases were female (n: 21$)$ and $47 \%$ were male (n: 19$)$. For the KA cases, $43 \%$ (n: 13 ) were female, while $57 \%$ (n: 17) were male. Lesions diagnosed as KA were generally well-circumscribed, symmetric lesions with a keratin-filled crater, surrounded by an irregularly thick layer proliferating squamous epithelium. Lesions diagnosed as SCC were well-differentiated with extensive keratinization but atypical keratinocytes infiltrating within the dermis.

Statistically significant differences were found between SCC and KA lesions in terms of the densities and levels of positive nuclear staining with Ki-67, p16, p21 and p53 $(p<0.05)$; however, no significant differences were observed with $\mathrm{p} 27$ ( $\mathrm{p}>0.05)$ (Table 1). A statistically significant correlation was discovered between the $\mathrm{Ki}-67$ and $\mathrm{p} 16$ positive nuclear staining intensities and the levels in SCC lesions $(\mathrm{p}=0.031, \mathrm{p}=0.025)$ and also between the Ki-67 and the $\mathrm{p} 16$ positive nuclear staining intensities and the levels in KA lesions $(\mathrm{p}=0.022, \mathrm{p}=0.031)$. Similarly, a statistically significant correlation was determined between the Ki-67 and p53 positive nuclear staining intensities and the levels in KA lesions $(\mathrm{p}=0.000, \mathrm{p}=0.000)$, and likewise between the Ki-67 and the p21 positive nuclear staining intensities and the levels in KA lesions ( $\mathrm{p}=0.001, \mathrm{p}=0.003$ ). The correlation between the Ki67 and the p27 positive nuclear staining intensities and the levels in KA lesions ( $\mathrm{p}=0.009$, $\mathrm{p}=0.009$ ) was statistically significant. Furthermore, a statistically significant correlation was revealed between the p16 and $\mathrm{p} 21$ positive nuclear staining intensities and the levels in KA lesions $(\mathrm{p}=0.009$, $\mathrm{p}=0.021)$ and a correlation was found between the $\mathrm{p} 53$ and p21 positive nuclear staining intensities and the levels in
KA lesions $(\mathrm{p}=0.003, \mathrm{p}=0.010)$. Finally, a statistically significant correlation was obtained between the p27 and p21 positive nuclear staining intensities and the levels in KA lesions $(\mathrm{p}=0.002, \mathrm{p}=0.003)$. The Ki-67 proliferation index was found to be higher in SCCs than in KAs in terms of both the level and the percentages ( $\mathrm{p}<0.05$ ). With Ki-67, complete staining and dense nuclear staining were observed in the full thickness epithelium the SCC lesions (Figure 1a). Staining was observed with Ki-67 in peripheral basal and supra-basal layers of KA lesions (Figure 1b). Positive nuclear staining with $\mathrm{Ki}-67$ was observed in keratinocytes in basal and suprabasal levels of non-neoplastic epithelium around the lesion. Both the level and staining intensities for $\mathrm{p} 16$ were higher in SCC lesions than those of the KA lesions $(p<0.05)$. While

TABLE 1. Immunohistochemical results of SCCs and KAs

\begin{tabular}{|c|c|c|c|}
\hline Immunohistochemical staining & & KA n $(\%)$ & $\mathrm{SCC} n(\%)$ \\
\hline \multirow[t]{3}{*}{ Ki-67 density } & 1 & $16(53.3)$ & $8(20)$ \\
\hline & 2 & 11 (36.6) & $18(45)$ \\
\hline & 3 & $3(10.1)$ & $14(35)$ \\
\hline \multirow[t]{3}{*}{ Ki-67 level } & 1 & $18(60)$ & $8(20)$ \\
\hline & 2 & $10(33.3)$ & $19(47.5)$ \\
\hline & 3 & $2(6.7)$ & $13(32.5)$ \\
\hline \multirow[t]{3}{*}{ p16 density } & 1 & $21(70)$ & $13(32.5)$ \\
\hline & 2 & $6(20)$ & $22(55)$ \\
\hline & 3 & $3(10)$ & $5(12.5)$ \\
\hline \multirow[t]{3}{*}{ p16 level } & 1 & $21(70)$ & $13(32.5)$ \\
\hline & 2 & $7(23.3)$ & $22(55)$ \\
\hline & 3 & $2(6.7)$ & $5(12.5)$ \\
\hline \multirow[t]{3}{*}{ p53 density } & 1 & $18(60)$ & $13(32.5)$ \\
\hline & 2 & $7(23.3)$ & $15(37.5)$ \\
\hline & 3 & $5(16.7)$ & $12(30)$ \\
\hline \multirow[t]{3}{*}{ p53 level } & 1 & $18(60)$ & $14(35)$ \\
\hline & 2 & $9(30)$ & $15(37.5)$ \\
\hline & 3 & $3(10)$ & $11(27.5)$ \\
\hline \multirow[t]{3}{*}{ p21 density } & 1 & $23(76.7)$ & $22(55)$ \\
\hline & 2 & $7(23.3)$ & $14(35)$ \\
\hline & 3 & $0(0)$ & $4(10)$ \\
\hline \multirow[t]{3}{*}{ p21 level } & 1 & $23(76.7)$ & $18(45)$ \\
\hline & 2 & $7(23.3)$ & $17(42.5)$ \\
\hline & 3 & $0(0)$ & $5(12.5)$ \\
\hline \multirow[t]{3}{*}{ p27 density } & 1 & $9(30)$ & $11(27.5)$ \\
\hline & 2 & $18(60)$ & $24(60)$ \\
\hline & 3 & $3(10)$ & $5(12.5)$ \\
\hline \multirow[t]{3}{*}{ p27 level } & 1 & $7(23.3)$ & $11(27.5)$ \\
\hline & 2 & $20(66.7)$ & $22(55)$ \\
\hline & 3 & $3(10)$ & $7(17.5)$ \\
\hline
\end{tabular}



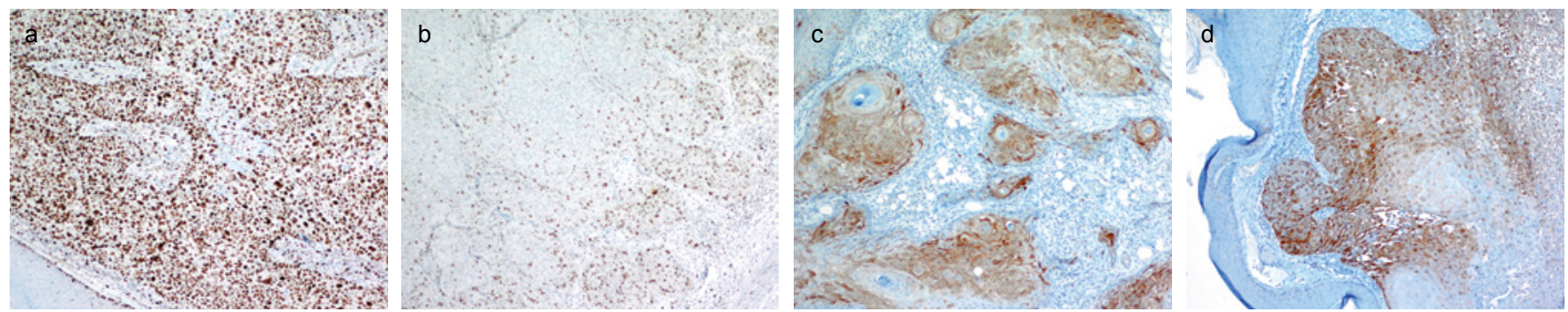

FIG. 1. a-d. In SCC, expression of Ki-67 is seen as a diffuse pattern showing positive nuclear staining through the full thickness of the lesion (X100) (a), in KA, expression of Ki-67 is seen in the peripheral basal and supra-basal layers of the lesion (X100) (b), in SCC, expression of p16 is shown as staining of a complete-layer in SCCs (X100) (c), in KA, expression of p16 is seen as nuclear and cytoplasmic staining observed in the peripheral basal and supra-basal layers of the lesion (X100) (d).
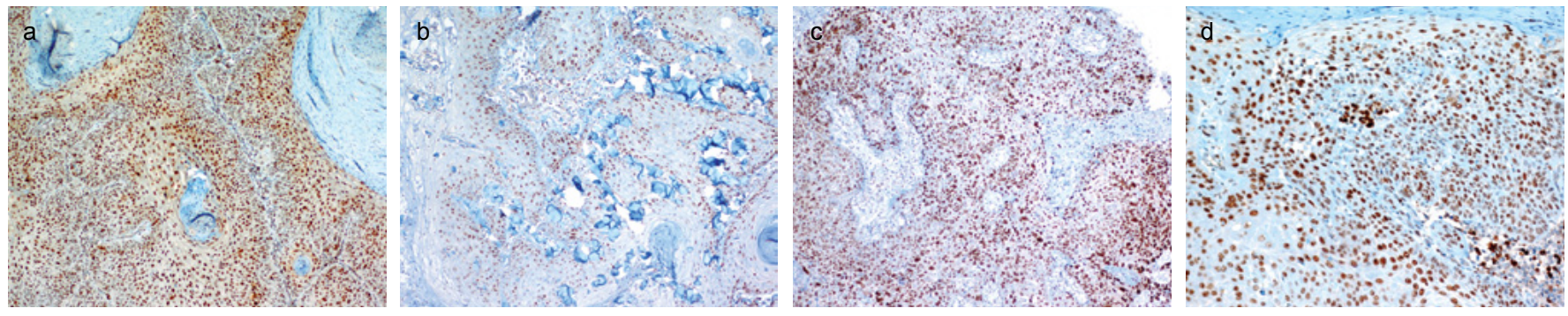

FIG. 2. a-d. In SCC, expression of 21 is shown as nuclear staining with a diffuse pattern of the lesion (X100) (a), in KA, expression of 21 is shown as nuclear staining in peripheral basal and suprabasal cells of the lesion (X100) (b), in SCC, expression of p27 is shown as nuclear staining with a diffuse pattern of the lesion (X100) (c), in KA, expression of 27 is shown as nuclear staining of the peripheral basal and supra-basal cells of the lesion (X200) (d).

nuclear and cytoplasmic staining with p16 was observed only in basal and supra-basal layers of KA lesions, strong positive staining was observed in the full thickness epithelium the SCC lesions (Figure 1c, 1d). Strong positive nuclear staining with p21 was observed in the full thickness epithelium the SCC lesions that were confined to the peripheral and supra-basal layers in well-differentiated SCC and KA lesions (Figure 2a, b). Both the level and staining intensities for p21 were higher in SCC lesions than those of the KA lesions $(\mathrm{p}<0.05)$. No difference was detected between SCC and KA lesions with p27 in terms of both the level and intensity of staining $(p>0.05)$ (Figure 2c, d). A significant difference in $\mathrm{p} 53$ was found between SCC lesions and KA lesions in terms of both the level and intensity of nuclear staining $(p<0.05)$. While diffused and complete-level staining were observed with p53 in the SCC lesions, the peripheral basal staining and supra-basal layer staining were mainly observed in KA lesions (Figure $3 a, b)$. The staining percentages and expression patterns (levels) of all immunohistochemical markers in the SCCs and KAs are summarized in Table 2.

\section{DISCUSSION}

Keratoacanthomas are usually benign epithelial skin tumors with the characteristics of rapid growth and spontaneous regression. KAs are frequently found on the hands and face, particularly on sun-exposed regions. In microscopic evaluation, KAs show similarities with well-differentiated SCCs (3). The classification of KAs is still controversial. Some authors consider them a subtype of well-differentiated SCCs, while others classify them as a pseudo-malignant tumor (12). Beham et al. (22) suggested that KAs are a clinically distinct variant of well-differentiated SCCs capable of spontaneous regression. Mandrell and Santa Cruz (23) also suggested that KAs are benign squamous proliferations diagnosed by biopsy according to the well-established clinicpathological criteria. Tronnier (24) reported that KAs are characterized by a keratin-filled crater showing rapid growth in the proliferation stage with a potential for spontaneous regression. Besides, KAs in the regression period should also be well-differentiated from verruca vulgaris. The final diagnosis of KAs is made by a histopathological examination. There may be some diagnostic problems distinguishing KAs from well-differentiated SCCs if there are deficient samples such as a shave excision on a lesion, curettage, or punch biopsy. For this reason, the biopsy method preferred in these tumors is total excision (25). Cribier et al. (26) revealed that, on their own, histopathological criteria are not sufficient for establishing a reliable distinction between KAs and SCCs. The authors also concluded that atypical and hard cases where no exact distinction can be made should be considered and treated as SCC. 


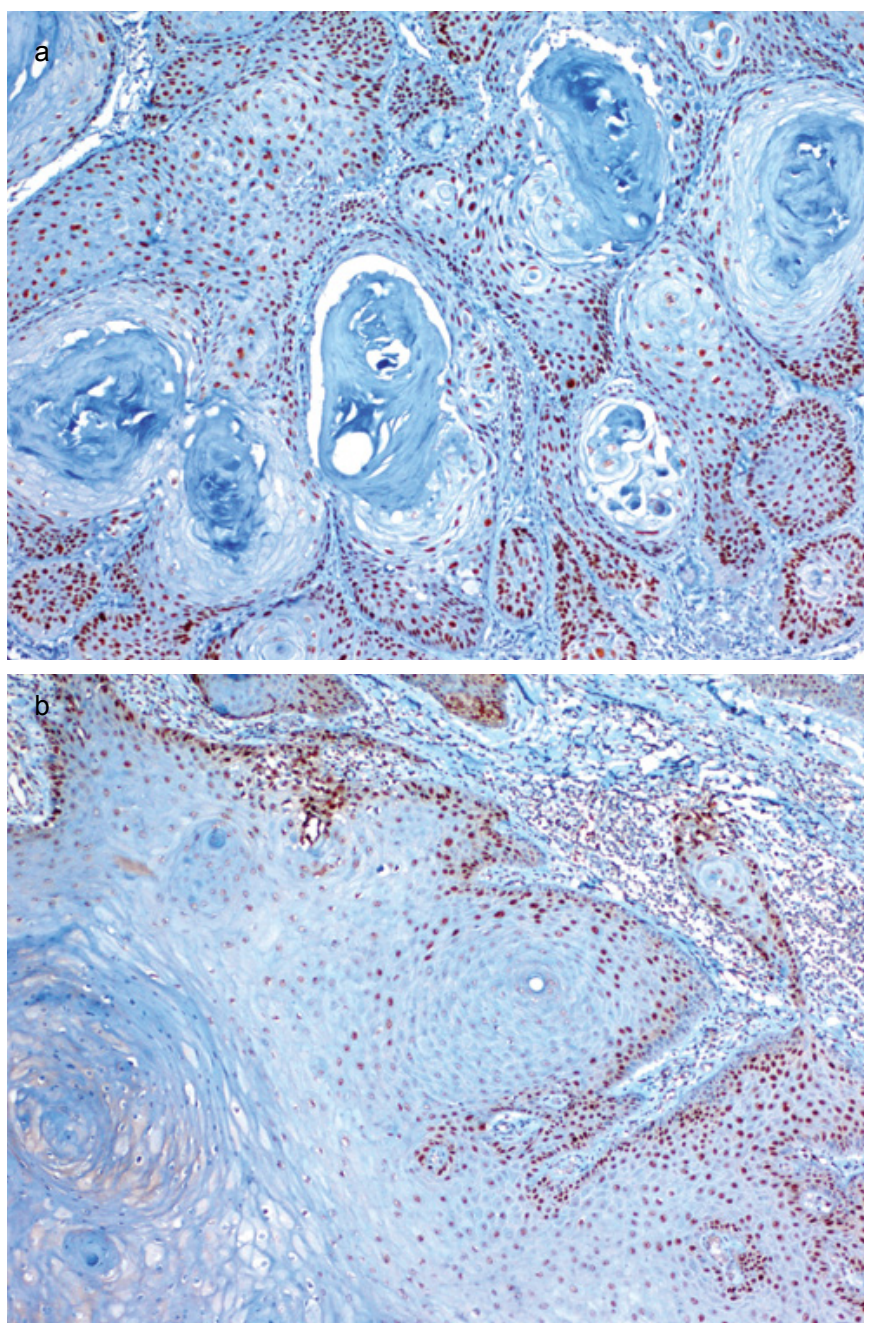

FIG. 3. a, b. In well-differentiated SCC, expression of p53 nuclear staining is shown in the peripheral basal and supra-basal cells of the lesion (X100) (a), in $\mathrm{KA}$, expression of 53 nuclear staining is shown in the peripheral basal and supra-basal cells of the lesion (X100) (b).

Some studies have used various immunohistochemical markers to distinguish between KAs and SCCs (6-15). Kaabipour et al. (12) investigated whether p16 expression is significant in distinguishing 24 infiltrative SCCs from 24 KAs. As a result of the study, they concluded that $\mathrm{p} 16$ has no diagnostic value in the definitive diagnosis of KAs and SCCs. In our study, a significant relationship was found between KAs and SCCs in relation to the level and density of staining with p16.

Kikuchi et al. (27) examined the expression of ras oncogene product p21 (p21-ras) and epidermal growth factor (EGF) receptor in various skin tumors containing KA and SCC. At the end of the study, they reported that EGF receptor expression is closely associated with cellular proliferation but p21-ras may play a role in the differentiation of cells in various skin tumors. Ahmed et al. (28) investigated p21WAF1/CIP1 expression in non-melanoma skin tumors including $\mathrm{SCC}, \mathrm{KA}, \mathrm{BCC}$,
TABLE 2. Statistical comparison of the immunohistochemical results of SCCs and KAs

\begin{tabular}{lccc}
\hline & SCC $(\mathrm{n}=40)$ & $\mathrm{KA}(\mathrm{n}=30)$ & $\mathrm{p}$ \\
\hline Age (min-max) & $74(39-92)$ & $71(35-89)$ & 0.105 \\
Sex (F/M) & $21 / 19$ & $13 / 17$ & 0.048 \\
Ki-67 density & $2.15 \pm 0.74$ & $1.57 \pm 0.68$ & 0.002 \\
Ki-67 level & $2.13 \pm 0.72$ & $1.47 \pm 0.63$ & 0.001 \\
p16 density & $1.80 \pm 0.65$ & $1.40 \pm 0.68$ & 0.007 \\
p16 level & $1.80 \pm 0.65$ & $1.37 \pm 0.62$ & 0.004 \\
p53 density & $1.98 \pm 0.80$ & $1.57 \pm 0.77$ & 0.031 \\
p53 level & $1.93 \pm 0.79$ & $1.50 \pm 0.68$ & 0.023 \\
p21 density & $1.55 \pm 0.68$ & $1.23 \pm 0.43$ & 0.042 \\
p21 level & $1.68 \pm 0.69$ & $1.23 \pm 0.43$ & 0.005 \\
p27 density & $1.85 \pm 0.62$ & $1.80 \pm 0.61$ & 0.744 \\
p27 level & $1.90 \pm 0.67$ & $1.87 \pm 0.57$ & 0.871 \\
\hline SCCs: squamous cell carcinomas; KAs: keratoacanthomas; F: female; M: male
\end{tabular}

SCCs: squamous cell carcinomas; KAs: keratoacanthomas; F: female; M: male

Bowen's disease (BD), actinic keratosis (AK), seborrheic keratosis and normal skin. In this study, cells with p21WAF1/ CIP1 stained more positively in SCC cases than in others. No positively stained cells were observed in BCC cases. Ahmed et al. (28) suggested that p21WAF1/CIP1 has some unidentified role in keratinocyte tumorigenesis, which may not be directly related to carcinogenesis. In our study, a significant relationship was found between KAs and SCCs in relation to the level and density of staining with p21.

Oh et al. (29) investigated the staining patterns of $\mathrm{BD}, \mathrm{AK}$ and SCC with p27 and Ki-67. While a linear staining pattern was observed for Ki-67 in basal and para-basal cells in normal skin and actinic keratosis, a diffuse staining pattern spanning all epithelial layers was observed in keratinocytes in the invasive centers of SCCs and BD. When compared with $\mathrm{BD}, \mathrm{AK}$, and normal epidermis, $\mathrm{p} 27$ exhibited a lower expression in the invasive centers of SCC. Oh et al. (29) suggested that the pattern of a combination of Ki-67 and p27 staining may be useful in supporting the differentiation of AK, BD and SCC. Hu et al. (30) examined expanding and regressing KAs for the expression of p27. At the end of the study, while there was little expression with KAs expanding with $\mathrm{p} 27$, nuclear staining was detected in the majority of atypical aggregates consisting of regressing keratinocytes in KAs. Hu et al. (30) suggested that p27 may play a role in promoting the regression of KA and is a potential target for pharmacological intervention. In our study, no significant relationship was detected between KAs and SCCs in relation to the level and density of staining with p27.

Cain et al. (6) investigated the expression of p53 and used proliferating cell nuclear antigen (PCNA) as an immunohistochemical marker to distinguish KA from both well-differentiated SCC and SCC with KA-like features. The authors 
reported that PCNA and p53 have not proved to be helpful in differentiating KA from KA-like SCC. They concluded that their findings support the hypothesis that these tumors represent a possible biologic spectrum. Connolly et al. (31) investigated the value of immunohistochemical staining patterns of bcl-2, Ki-67, and p53 in distinguishing subungual KA from subungual SCC. No subungual KA staining was detected with Ki-67 while some subungual SCCs were stained. In p53, a higher staining index was detected in subungual SCCs in relation to subungual KAs. The authors concluded that immunohistochemistry for $\mathrm{p} 53$ and Ki-67 can help to distinguish a subungual SCC from a subungual KA. In a study by Borkowski et al. (20), the accumulation of p53 protein in 26 KAs and 4 normal skin biopsies was compared. Positive nuclear staining was detected in 20 of $26(77 \%)$ of the KAs and in none of the normal skin samples. Nuclear staining occurred in the outer most layer of the tumors and not in the keratin-filled central cores. Borkowski et al. (20) suggested that in SCCs that are histologically similar to KA, the accumulation of $\mathrm{p} 53$ protein may indicate the progression to malignancy. In our study, nuclear positive staining was detected for $\mathrm{p} 53$ in various densities in all of our KA cases. Skalova and Michal (11) investigated the cell proliferation pattern in actinic KAs and SCCs using an MIB-1immunohistochemical marker. At the end of the study, they concluded that the proliferation patterns of these two tumors are different from each other. Vasiljevic et al. (1) observed a similar staining pattern in SCCs and KAs with Ki67 and p53 in their study. However, they detected a stronger staining with both immunohistochemical markers in the tumor relative to the tissues around the lesion. Batinac et al. (19) investigated $\mathrm{p} 53$ and $\mathrm{Ki}-67$ expression in various non-neoplastic (normal skin, psoriatic skin) and neoplastic skin lesions (KA, $\mathrm{BCC}$, and $\mathrm{SCC}$ ). At the end of the study, they found that the expressions of $\mathrm{p} 53$ and Ki-67 differed between the groups. They concluded that $\mathrm{p} 53$ protein overexpression is observed in neoplastic skin lesions in particular, but that there may be expression in sun-exposed squamous epithelium of elderly people or in inflammatory skin diseases such as psoriatic skin. The authors also suggested that the Ki-67 proliferation index and $\mathrm{p} 53$ protein expression indicate the level of malignancy in an examination of cutaneous neoplasms. Lu et al. (16) investigated the staining density and pattern of p53, p21, PCNA, and Ki-67 in pre-malignant and malignant skin lesions. In 83.3\% of KAs, mid-density staining was observed with p53. While low-density staining with PCNA and p21 was observed in KA lesions, mid-density expression was observed with Ki-67 in $83.3 \%$ of the samples. In $60 \%$ of SCCs, the staining density with p53 was weak; in $83.3 \%$ of SCCs there was mid-density staining, and in $71.4 \%$ the staining density was severe. In SCC lesions, mid-level or dense expression was generally observed with Ki-67 and PCNA. In general, there was little expression of p21 in KA and SCC lesions. In normal epidermis around the lesion, while expression was observed with Ki-67 in basal cells and some parabasal cells, no staining was detected with p53 (16). In our study, a statistically significant relationship was found between KAs and SCCs for p53, p21 and Ki-67 in relation to both the level and density of staining. With these immunohistochemical markers, weak staining (Grade I) was observed in non-neoplastic regions in the basal/supra-basal layer (level I) around the lesion.

In conclusion, the differential diagnosis of well-differentiated SCCs with KA-like features and KAs can be difficult in some cases due to the similarities in the histopathological findings. The results of the research presented in this paper led us to conclude that an examination of $\mathrm{p} 16, \mathrm{p} 21$, and $\mathrm{p} 53$ expression and the Ki-67 proliferation index can be useful in the differential diagnosis between well-differentiated SCCs and KAs.

Ethics Committee Approval: Ethics committee approval was received for this study from the ethics committee of Recep Tayyip Erdoğan University School of Medicine (23 November 2012, Meeting number: 2012/155).

Informed Consent: Written informed consent was obtained from patients who participated in this study.

Peer-review: Externally peer-reviewed.

Author contributions: Concept - R.B., H.G., İ.Ş.; Design - R.B., İ.Ş., P.B.; Supervision - R.B., İ.Ş., C.Y.; Resource - R.B., H.G., İ.Ş.; Materials - R.B., H.G., P.B.; Data Collection and/or Processing - R.B., H.G., İ.Ş.; Analysis and/or Interpretation - R.B., P.B., P.Ü.; Literature Search - R.B., H.G., P.B.; Writing - R.B; Critical Reviews - R.B., İ.Ş.

Conflict of Interest: The authors state no conflict of interest.

Financial Disclosure: This study has receieved financial support from Recep Tayyip Erdoğan University Scientific Research Support Fund.

\section{REFERENCES}

1. Vasiljevic N, Andersson K, Bjelkenkrantz K, Kjellström C, Mansson H, Nilsson E, et al. The Bcl-xL inhibitor of apoptosis is preferentially expressed in cutaneous squamous cell carcinoma compared with that in keratoacanthoma. Int J Cancer 2009; 124:2361-6. [CrossRef]

2. Stern RS. The mysteries of geographic variability in nonmelanoma skin cancer incidence. Arch Dermatol 1999;135:843-4. [CrossRef]

3. Schwartz RA. Keratoacanthoma. J Am Acad Dermatol 1994;30:1-19. [CrossRef] 
4. Ko CJ .Keratoacanthoma: facts and controversies. Clin Dermatol 2010;28:254-61. [CrossRef]

5. Kingman J, Callen JP. Keratoacanthoma. A clinical study. Arch Dermatol 1984;120:736-40. [CrossRef]

6. Cain CT, Niemann TH, Argenyi ZB. Keratoacanthoma versus squamous cell carcinoma. An immunohistochemical reappraisal of p53 protein and proliferating cell nuclear antigen expression in keratoacanthoma-like tumors. Am J Dermatopathol 1995;17:324-31.

7. Putti TC, Teh M, Lee YS. Biological behavior of keratoacanthoma and squamous cell carcinoma: telomerase activity and COX2 as potential markers. Mod Pathol 2004;17:468-75. [CrossRef]

8. Ho T, Horn T, Finzi E. Transforming growth factor alpha expression helps to distinguish keratoacanthomas from squamous cell carcinomas. Arch Dermatol 1991;127:1167-71. [CrossRef]

9. Takeda H, Kondo S. Differences between squamous cell carcinoma and keratoacanthoma in angiotensin type-1 receptor expression. Am J Pathol 2001;158:1633-7. [CrossRef]

10. Melendez ND, Smoller BR, Morgan M. VCAM (CD-106) and ICAM (CD-54) adhesion molecules distinguish keratoacanthomas from cutaneous squamous cell carcinomas. Mod Pathol 2003;16:8-13. [CrossRef]

11. Skalova A, Michal M. Patterns of cell proliferation in actinic keratoacanthomas and squamous cell carcinomas of the skin. Immunohistochemical study using the MIB 1 antibody in formalin-fixed paraffin sections. Am J Dermatopathol 1995; 17:332-4.

12. Kaabipour E, Haupt HM, Stern JB, Kanetsky PA, Podolski VF, Martin AM. p16 expression in keratoacanthomas and squamous cell carcinomas of the skin: an immunohistochemical study. Arch Pathol Lab Med 2006;130:69-73.

13. Kuivanen TT, Jeskanen L, Kyllönen L, Impola U, SaarialhoKere UK. Transformation-specific matrix metalloproteinases, MMP-7 and MMP-13, are present in epithelial cells of keratoacanthomas. Mod Pathol 2006;19:1203-12. [CrossRef]

14. Mukunyadzi P, Sanderson RD, Fan CY, Smoller BR. The level of syndecan-1 expression is a distinguishing feature in behavior between keratoacanthoma and invasive cutaneous squamous cell carcinoma. Mod Pathol 2002;15:45-9. [CrossRef]

15. Batinac T, Zamolo G, Coklo M, Hadzisejdic I, Stemberger C, Zauhar G. Expression of cell cycle and apoptosis regulatory proteins in keratoacanthoma and squamous cell carcinoma. Pathol Res Pract 2006;202:599-607. [CrossRef]

16. Lu S, Tiekso J, Hietanen S, Syrjänen K, Havu VK, Syrjänen S. Expression of cell-cycle proteins p53, p21 (WAF-1), PCNA and Ki-67 in benign, premalignant and malignant skin lesions with implicated HPV involvement. Acta Derm Venereol 1999;79:268-73. [CrossRef]

17. Michieli P, Chedid M, Lin D, Pierce JH, Mercer WE, Givol D. Induction of WAF1/CIP1 by a p53-independent pathway. Cancer Res 1994;54:3391-5.
18. Fillies T, Woltering M, Brandt B, Van Diest JP, Werkmeister R, Joos $\mathrm{U}$, et al. Cell cycle regulating proteins p21 and p27 in prognosis of oral squamous cell carcinomas. Oncol Rep 2007;17:355-9. [CrossRef]

19. Batinac T, Zamolo G, Jonjic N, Gruber F, Petrovecki M. p53 protein expression and cell proliferation in non-neoplastic and neoplastic proliferative skin diseases. Tumori 2004;90:120-7.

20. Borkowski A, Bennett WP, Jones RT, Borkowski P, Harris CC, Ferreira LR, et al. Quantitative image analysis of p53 protein accumulation in keratoacanthomas. Am J Dermatopathol 1995; 17:335-8.

21. Bordbar A, Dias D, Cabral A, Beck S, Boon ME. Assessment of cell proliferation in benign, premalignant and malignant skin lesions. Appl Immunohistochem Mol Morphol 2007;15:229-35. [CrossRef]

22. Beham A, Regauer S, Soyer HP, Beham-Schmid C. Keratoacanthoma: a clinically distinct variant of well differentiated squamous cell carcinoma. Adv Anat Pathol 1998;5:269-80. [CrossRef]

23. Mandrell JC, Santa Cruz D. Keratoacanthoma: hyperplasia, benign neoplasm, or a type of squamous cell carcinoma? Semin Diagn Pathol 2009;26:150-63. [CrossRef]

24. Tronnier M. [Keratoacanthoma. A variant of highly differentiated squamous cell carcinoma and its differential diagnosis]. Pathologe 2002;23:65-70. [CrossRef]

25. Karaa A, Khachemoune A. Keratoacanthoma: a tumor in search of classification. Int J Dermatol 2007;46:671-8. [CrossRef]

26. Cribier B, Asch P, Grosshans E. Differentiating squamous cell carcinoma from keratoacanthoma using histopathological criteria. Is it possible? A study of 296 cases. Dermatology 1999;199:208-12. [CrossRef]

27. Kikuchi A, Amagai M, Hayakawa K, Ueda M, Hirohashi S, Shimizu N, et al. Association of EGF receptor expression with proliferating cells and of ras $\mathrm{p} 21$ expression with differentiating cells in various skin tumours. Br J Dermatol 1990;123:49-58. [CrossRef]

28. Ahmed NU, Ueda M, Ichihashi M. p21WAF1/CIP1 expression in non-melanoma skin tumors. J Cutan Pathol 1997;24:223-7. [CrossRef]

29. Oh CW, Penneys N. P27 and Mib1 expression in actinic keratosis, Bowen disease, and squamous cell carcinoma. Am J Dermatopathol 2004;26:22-6. [CrossRef]

30. $\mathrm{Hu} \mathrm{W}$, Cook T, Oh CW, Penneys NS. Expression of the cyclindependent kinase inhibitor p27 in keratoacanthoma. $J$ Am Acad Dermatol 2000;42:473-5. [CrossRef]

31. Connolly M, Narayan S, Oxley J, de Berker DA. Immunohistochemical staining for the differentiation of subungual keratoacanthoma from subungual squamous cell carcinoma. Clin Exp Dermatol 2008;33:625-8. [CrossRef] 